\title{
Investigation of in vivo and in vitro fertilization methods: a review of the literature
}

\author{
José Guedes da Silva Júnior*1, Daniel José da Silva², João Ricardhis Saturnino de Oliveira1, \\ Weber Melo do Nascimento1, Maria Auxiliadora Macêdo Callou³, Talyta Valéria Siqueira do Monte ${ }^{4}$ \\ 'Universidade Federal de Pernambuco (UFPE), Departamento de Bioquímica, Recife, PE, Brasil \\ ${ }^{2}$ Faculdade Sete de Setembro (FASETE), Paulo Afonso, BA, Brasil \\ ${ }^{3}$ Faculdade de Juazeiro do Norte (FJN-CE), Juazeiro do Norte, CE, Brasil \\ ${ }^{4}$ Hospital Otávio de Freitas (HOF), Departamento de Traumatologia e Ortopedia, Recife, PE, Brasil
}

\section{Abstract}

Objectives: This is a review of the methods of assisted reproduction, in vivo and in vitro fertilization, and its applications. Methods: The aforementioned information was compiled through a review of the literature on articles, books and periodicals about Intrauterine Transfer (IT), In Vitro Fertilization (IVF), Intracytoplasmic Injection (ICSI), Gamete Intrafallopian Transfer (GIFT), and ZygoteIntrafallopian Transfer (ZIFT). Results: The exacerbated use of these techniques brought peculiar attention on the subject although population was discordant about its use. This formed non-veridical opinions regarding the process. Manipulation of these therapies has been controlled and enacted by laws, legislations, and resolutions by each country politics, yet these techniques are well sought and present satisfactory results. Conclusions: Assisted human reproduction gives hope and brings greater understanding and confidence to those who are facing problems to build a family. The search for specialized clinics has become more frequent for those who wish to have children and are not limited to this, it has the possibility to deviate from hereditary genetic problems, since it contributes as an improvement in the health of a new generation.

Keywords: assisted reproduction; in vivo fertilization; infertility; human reproduction.

\section{Introduction}

Assisted human reproduction (AHR) represents a group of advanced technologies manipulated for the procreation of humans. The first technique developed was artificial insemination in vivo, followed by in vitro fertilization, which brought good results, such as the birth of the first test-tube baby in England, Louise Brown, in 1978 and in Brazil, Anna Paula Caldeira, in 1984. These and other AHR techniques were developed with the purpose of solving inherited and acquired reproductive problems, in peculiar cases of the gender involved such as infertility and sterility, gestation in same sex couples, and in cases that allow the generation of children without complications of diseases, genetic malformations, and chronic diseases. ${ }^{1}$

The specificities and sensitivities of the various methods demonstrate the numerous successful technological advances in the field. However, the AHR technique has brought many controversial issues, due to its actions of competence and legality. Even with the regulation that exists today in Brazil, which regulates which professions are qualified to act in the area and to who is the competence of each in each method, there is still a lot of misinformation about it. This creates prejudice and inhibits a wider use of AHR by the population.

In this context, the need for greater clarification of the techniques, procedures, legal issues, necessities, limitations and applicability of the AHR for health professionals and for the general population as proposed by this project arises.

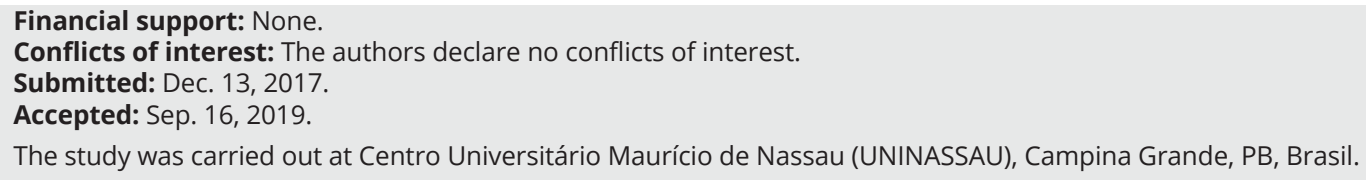

Copyright Silva Júnior et al. This is an Open Access article distributed under the terms of the Creative Commons Attribution License, which permits unrestricted use, distribution, and reproduction in any medium, provided the original work is properly cited. 
In order to discuss and contribute to the clarification of these questions, the present study deals with an analysis of the various methods used in assisted reproduction, in vivo and in vitro fertilization, and its usefulness in medicine.

\section{Material and methods}

This study was developed through a review of the literature, with research of articles in scientific journals on the main methodologies of in vitro fertilization. The search was conducted in the following databases: PubMed, Medlineand Science Direct.Articles in Portuguese, English and Spanish were accepted for the preparation of the paper and they had to be available in full text. There was no delimitation of the year for this review.

\section{Results and discussion}

\section{Assisted Reproductive Techniques (ART)}

Faced with the concern of cases of infertility, the solution of this dilemma was searched by medical, biological and genetic professionals. The high cost of ART made it impossible for adults willing to have children to be carried out, so the options that allowed them to wait for their arrival had huge queues or they had to choose to be part of that group that opted for adoption. Today, the search for ART has become more frequent for couples who want to build a family and do not get results through the natural mode of reproduction.Assisted reproduction is the process of joining the technological practices with the intention of human procreation that suffers with problems that prevent the formation of a gestation. The procedure is composed of techniques directed to each couples necessities: In Vivo Fertilization, Intrauterine Insemination (II), In Vitro Fertilization (IVF), Intracytoplasmic Sperm Injection (ICSI), Gametes IntrafallopianTransfer (GIFT), Zygote IntrafallopianTransfer (ZIFT). ${ }^{2-4}$

An assisted reproductive technique can be classified as intracorporeal, when fertilization is performed inside the woman's body or as extracorporeal, when fertilization is manipulated in the laboratory and then introduced into the woman's uterine cavity. The technique is classified as homologous when using biological mate- rial of the couple and heterologous when there is the use of gamete donations. ${ }^{5}$

\section{Intrauterine Insemination (II)}

Intrauterine Insemination, the first technique launched in ART, is considered less complex and at a more affordable cost, defined as the introduction of male gametes into the uterine cavity, with the goal of in vivo fertilization, that is, in a natural way. ${ }^{6,7}$ The method is requested in cases of women with endometriosis, dysfunction in ovulation, poor quality of the cervical mucus, and homoaffectives, but the technique should be used if the fallopian tubes have perfect conditions. Insemination can be performed in a homologous or heterologous way, when there is presence of hereditary diseases and sterility. 8

Initially, ovulation induction is necessary for oocyte retrieval. The application of hormones to induce an ovulation has brought a high percentage of success in gestation, by allowing a greater formation of follicles, which leaves aside the use of the technique in normal menstrual cycle. The ovulatory induction is performed with hormone dosage at the beginning of the menstrual cycle, accompanied by ultrasonography that allows the visualization of the moment of ovulation, in this way the selected spermatozoa will be inseminated. Although a greater number of follicular formation occurs, treatment should be canceled when several follicles are formed, and a new cycle begins with a lower hormonal dosage. ${ }^{10}$

Collection of the masculine material is done by masturbation, preferably. Then, the selection of spermatozoa is processed through selecting those with better motility and morphology. The possibility of a gestation can reach between $22 \%$ and $33 \%$, after four attempts, this percentage suffers a decline and another technique will be recommended. ${ }^{10}$

\section{In Vitro fertilization (IVF)}

The in vitro method allows extracorporeal fertilization, as well as implantation of embryos derived from oocytes from donors. This technique allows a greater percentage of effectiveness due to its manipulation, the formation of larger amounts of oocytes, and the uterine implantation of fertilized embryos. ${ }^{5}$

The use of ovulation induction, the formation of zygotes and the amount of them that is transferred stand out in a worrisome function, because it causes multiple pregnancy and hyperstimulation syndrome. In the debate, some authors are in favor of reducing ovulation inducers dosage in order to avoid complications.11,12 Their indication is based on the final diagnosis of the tests performed by the couple, in which the presence of tubal problems, endometriosis, and moderate male problems are found. Initially, the biological material, both female and male, is received. The seminal fluid is used after the passage of liquefaction,deposited in a tube for a seminal clearance, and centrifugation. This process allows the 
separation of the seminal fluid and the spermatozoa, those with the capacity to occur insemination in the oocytes are selected, then, deposited in the same plate. Oocytes are observed under a microscope in a petri dish where they will be identified according to their maturity. And then, deposited and incubated in exclusive culture medium for 2 to 3 hours to receive the spermatozoa. ${ }^{13}$

After material incubation, fertilization is observed in about 19 hours. After 24 hours, cleavage can be seen, and pre-embryos formationis visualized. Some studies say that the pre-embryos ready to be transferred are those with a higher amount of blastomeres. In this method, pre-embryos with 8 or more blastomers are safer to use. The pre-embryos can be used up to 120 days, totaling 10 cells, which depends on several cases. In the transfer, the amount of embryos should be considered according to the determination by the CFM, avoiding complications. ${ }^{13}$

\section{Intracytoplasmic sperm injection}

Intracytoplasmic Sperm Injectionis used within IVF, where only one sperm is introduced into an oocyte. ICSI is the best indication when the problem in the fertility is the man, or in cases when the IVF does not bring satisfactory results. Although widely used today, ICSI does not ensure satisfactory results, its response can differentiate between $30 \%$ and $90 \%$ of correct answers. Although it is directed to problems in the semen or in the gamete, even so, the technique brings a large number of cases with satisfactory answers. ${ }^{14-16}$

The procedure requires follicular aspiration. In this phase, the use of vaginal ultrasonography allows a greater view of follicular uptake, then oocyte identification and classification are performed and placed in petri dish with specific culture medium. The sperm preparation is performed with the separation and selection of good quality spermatozoa. The next step is sperm injection into the oocyte, a phase that highlights high technology in fertility. ${ }^{14,15}$

\section{Gametes Intrafallopian Transfer and ZygotesIntrafallopian Transfer (GIFT and ZIFT)}

Although GIGT and Zift techniques were widely used in the past, they have been abandoned in clinical practice nowadays. The GIFT technique is based on the introduction of the male and female material into the uterine tubes of the carrier. Initially, ovulation and oocyte uptake must be manipulated. Spermatozoa are collected and prepared, selecting those that are faster and with a good morphology. With the aid of a catheter, the material is transferred to the uterine tubes. In the ZIFT technique, the procedure is equal to the GIFT technique.There is an induction and collection of eggs, collection and seminal preparation. Then the material is placed on a plate to occur the fusion, which characterizes this method as in vitro, then, the zygote is transferred to the uterine tubes. That is, GIFT and ZIFT are similar techniques with difference in the fertilization process although both have in vivo, and in vitro parts. ${ }^{6,17}$

\section{Conclusions}

The objective of this paper was to analyze the different methods of assisted reproduction in order to explore informative knowledge of contents that surround this dilemma, aiming that the subjects discussed in this paper can bring a relevance to the academic population and society.

\section{References}

1. Moura MD, Souza MCB, Sheffer BB. Reprodução assistida. Um pouco de história. Rev SBPH (Belo Horizonte). 2009;12:23-42.

2. Pádua ARM. Responsabilidade civil na reprodução assistida. Rio de Janeiro: Lumem Juris; 2008. p. 56.

3. Gabiatti JRE, Faúndes A, Bahamondes L, Faúndes D, Ramos M, Fazano F. A experiência de iniciar um programa de fertilização in vitro em Hospital Universitário. ReprodClim. 1998;13:221-7.

4. Freitas M, Siqueira AAFA, Segre CAM. Avanços em reprodução assistida. Rev Bras Crescimento Desenvolv Hum, 2008;18(1):93-7.

5. Souza MC. As técnicas de reprodução assistida. A barriga de aluguel. A definição da maternidade e da paternidade. Bioética. Revista da EMERJ. 2010;13:348-67.

6. $\quad$ Diniz MH. O estado atual do biodireito. Saraiva. 2011;37:1025.

7. Duran HE, Morshedi M, Kruger T, Oehninger S. Intrauterine insemination: a systematic review on determinants of success. Hum Reprod Update. 2002;8(4):373-84. http://dx.doi.org/10.1093/humupd/8.4.373. PMid:12206471.

8. Yavuz A, Demirci O, Sözen H, Uludoğan M. Predictive factors influencing pregnancy rates after intrauterine insemination. Iran J Reprod Med. 2013;11(3):227-34. PMid:24639750.

9. $\quad$ Eshre Capri Workshop Group. Intrauterine insemination. Hum Reprod Update. 2009;15(3):265-77. http://dx.doi.org/10.1093/ humupd/dmp003.

10. Nuojua-Huttunen S, Tomas C, Bloigu R, Tuomivaara L, Martikainen H. Intrauterine insemination treatment in subfertility: an analysis of factors affecting outcome. Hum Reprod. 1999;14(3):698-703. http://dx.doi.org/10.1093/humrep/14.3.698. PMid:10221698. 
11. Villasante A, Pacheco A, Ruiz A, Pellicer A, Garcia-Velasco JA. Vascular endothelial cadherin regulates vascular permeability: implications for ovarian hyperstimulation syndrome. J Clin Endocrinol Metab. 2007;92(1):314-21. http://dx.doi.org/10.1210/ jc.2006-1231. PMid:17032719.

12. Abu-Hassan D, Al-Hasani S. The use of ICSI for all cases of in-vitro conception. Hum Reprod. 2003;18(4):893-4, author reply 894-5. http://dx.doi.org/10.1093/humrep/deg159. PMid:12660298.

13. Van Voorhis BJ. Outcomes from assisted reproductive technology. Obstet Gynecol. 2006;107(1):183-98. http://dx.doi.org/10.1097/01. AOG.0000194207.06554.5b. PMid:16394060.

14. Palermo G, Joris H, Devroey $P$, Van Steirteghem AC. Pregnancies after intracytoplasmic injection of a single spermatozoon into a oocyte. Lancet. 1992;340(8810):17-8. http://dx.doi.org/10.1016/0140-6736(92)92425-F. PMid:1351601.

15. Nagy Z, Liu J, Cecile J, Silber S, Devroey P, Van Steirteghem A. Using ejaculated, fresh, and frozen-thawed epididymal and testicular spermatozoa gives rise to comparable results after intracytoplasmic sperm injection. Fertil Steril. 1995;63(4):808-15. http:// dx.doi.org/10.1016/S0015-0282(16)57486-X. PMid:7890067.

16. Dubey AK, Penzias AS, Emmi AE, Layman LC, Reindollar RH, Ducibella T. Failed fertilization after intracytoplasmic sperm injection: the extent of paternal and maternal chromatin decondesation. Fertil Steril. 1997;68(4):714-7. http://dx.doi.org/10.1016/S00150282(97)00313-0. PMid:9341616.

17. Abyholm T, Tanbo T. GIFT, ZIFT, and related techniques. Curr Opin Obstet Gynecol. 1993;5(5):615-22.

\section{*Correspondence}

José Guedes da Silva Júnior

Universidade Federal de Pernambuco (UFPE), Centro de Biociências, Departamento de Bioquímica

Av. Professor Moraes Rego, s/n, Bairro Cidade Universitária

CEP 50670-420, Recife, PE, Brasil

Tel.: +55 (81) 2126-8540

E-mail: zeguedescrizant@gmail.com

\section{Author information}

JGSJ - PhD in Biochemistry and Physiology, Universidade Federal de Pernambuco (UFPE). DJS - Bachelor of Biomedicine, Faculdade Sete de Setembro (FASETE). JRSO - MSc in Biochemistry and Physiology, Universidade Federal de Pernambuco (UFPE). WMN - PhD in Biochemistry and Physiology, Universidade Federal de Pernambuco (UFPE). MAMC - MSc in Public Policies with emphasis in Health, Atenas College University (ACU). TVSM Nurse with Expertise in traumatology and orthopedics, Instituto Materno Infantil de Pernambuco (IMIP).

\section{Author contributions}

DJS collected data and wrote the first draft. JGSJ designed the study, collected data and wrote the final draft. JRSO and WMN wrote the final draft. MAMC and TVSM designed the study and revised all versions. 